\title{
INTERFEROMETRIC SYNTHETIC APERTURE RADAR (INSAR) TECHNOLOGY AND GEOMORPHOLOGY INTERPRETATION
}

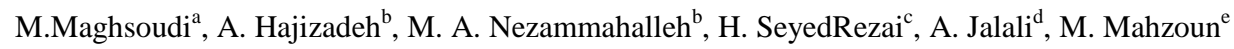 \\ ${ }^{a}$ Associate Professor, Physical Geography Department, Geography Faculty, University of Tehran, Tehran Iran \\ maghsoud@ut.ac.ir \\ ${ }^{\mathrm{b}} \mathrm{PhD}$ Student, Physical Geography Department, University of Tehran, Tehran, Iran \\ ab_hajizadeh@ut.ac.ir,mnezammahalleh@ut.ac.ir
}

${ }^{\mathrm{c}}$ Dept. of Remote Sensing and GIS, Islamic Azad University, Science and Research Branch

set_sr@yahoo.com

${ }^{\mathrm{d}}$ Department of Geography, Islamic Azad University, Tehran Markaz Branch, Tehran, Iran

neshat1366@yahoo.com

${ }^{\mathrm{e}}$ Master of Cartography, Iran Geographical Organization

mohammad60asadi@gmail.com

KEY WORDS: INSAR, Geomorphology, Hazard

\begin{abstract}
Geomorphology is briefly the study of landforms and their formative processes on the surface of the planet earth as human habitat. The landforms evolution and the formative processes can best be studied by technologies with main application in study of elevation. Interferometric Synthetic Aperture Radar (InSAR) is the appropriate technology for this application. With phase differences calculations in radar waves, the results of this technology can extensively be interpreted for geomorphologic researches. The purpose of the study is to review the geomorphologic studies using InSAR and also the technical studies about InSAR with geomorphologic interpretations. This study states that the InSAR technology can be recommended to be employed as a fundamental for geomorphology researches.
\end{abstract}

\section{INTRODUCTION}

Geomorphology as the study of landforms and their formative processes is a multidisciplinary field most strongly associated with the geographic and geological sciences (Sack and Orme, 2013).Geomorphology as a science describes surface terrain on the planet earth and explains the processes making the landforms and elevation changes (Murray et al, 2009). As a goal the science of geomorphology try to clarify the causes for the occurrences of morphological features of the earth, their topography and geographical distribution and also their evolution over time in order to recognize the roles they may play directly or indirectly in human societies (Harden, 2013; Murray et al, 2009). All the features on the earth may have displacements and changes in different time scales (Murray et al., 2009). For a thorough exploration and a better understanding of the earth objects, it is important to determine the rates of their movement in plane and height directions. The modern technologies help researchers in the field conduct their studies ever more accurately and rapidly (Slaymaker, 2001) about the landform movements. Interferometric Synthetic Aperture Radar (InSAR) is a technique appropriate to measure these movements. The technique uses some scenes of images to measure deformations and displacements based on geometric principles and radar wavelength properties using appropriate software programming (Gutierrez et al., 2011; Wadge et al., 2011; Ebmeier et al., 2012). It has a great potential in the field of geomorphology (Gutierrez et al., 2011).

InSAR is a method that can be applied to measure displacements and elevation changes of landforms using the phase difference between two Radar acquisitions (Gutierrez et al., 2011; Massonnet et al., 1995). It uses radar waves transmitted from spaceborne antennae and backscattered from the earth surface to measure changes between different radar acquisitions in different periods (Liu et al., 2013; Ebmeier et al., 2012).As Radar waves are sensitive to elevation changes in earth surface and topography, it would be possible to detect elevation changes in millimeter for different time intervals using two images or a time series of images. Therefore, it will be useful to recognize spatial and temporal changes in elevation for interpretation of processes and forms on the earth surface. This will help avoid adverse effect of many hazards and environmental issues.

So far, the researches concerning InSAR can broadly be divided into two categories. The first group contains the studies that applied INSAR technique to monitor some human and natural 
phenomenon or analyze an issue on the earth surface (Wechsler et al., 2009; Garcia and Mahan, 2012; Waele et al., 2011; Ruch et al., 2008; Liu et al., 2013; Gutierrez et al., 2011; Intrieri et al., 2013). The other group includes the studies that have attempted to improve accuracy and enhance the results of the technique or recognize validation and comparison between applications and uncertainties (Goudarzi et al., 2011; Zhou et al., 2012; Catterjee et al., 2009; Nolesini et al., 2013; Tralli et al., 2005; Kruse, 2012; Champenois et al., 2012; Riddick et al., 2012;Zhao et al., 2012). There are many researches about the application of the technique in a few geomorphology processes and forms (Wechsler et al., 2009; Wadge et al., 2009; Zhao et al., 2012; Metternicht et al., 2005; Ebmeier et al., 2012; Goudarzi et al., 2011; Intrieri et al., 2013) but there is no comprehensive study to explicitly review capabilities and applications of the technique in different fields of geomorphology. The evidence and interest in studies using this method are ever increasing. From Table 1 it can be understood that the studies about InSARtechnology is increasing over time so that before 1950 there was certainly no studies about the technology. The number of articles and books with InSAR application in geomorphology related studies in ever increasing so that it increased from a few before 2000 up to 270 articles and books in the middle of 2013 as it was reported by Scopus database.

\begin{tabular}{|c|c|c|c|c|}
\hline \multirow[b]{2}{*}{ Periods } & \multirow{2}{*}{$\begin{array}{l}\text { No. of } \\
\text { ArticleS }\end{array}$} & \multirow{2}{*}{$\begin{array}{l}\text { No. of } \\
\text { Books }\end{array}$} & \multicolumn{2}{|c|}{ InSAR in geomorphology } \\
\hline & & & $\begin{array}{c}\text { No. of } \\
\text { Articles }\end{array}$ & $\begin{array}{l}\text { No. of } \\
\text { Books }\end{array}$ \\
\hline $\begin{array}{l}1950- \\
2000\end{array}$ & 62 & 2 & 1 & 0 \\
\hline $\begin{array}{l}2000- \\
2005\end{array}$ & 276 & 18 & 33 & 2 \\
\hline $\begin{array}{l}2005- \\
2010\end{array}$ & 896 & 55 & 157 & 16 \\
\hline $\begin{array}{l}2010- \\
2014\end{array}$ & 1218 & 73 & 231 & 39 \\
\hline
\end{tabular}

Table 1: the table indicates the number of articles and books about InSAR and with InSAR application. (From Scopus Website)

In this study the INSAR techniques are clarified and a review is provided about different application of the technique in geomorphology researches. Following each application the results are interpreted in terms of geomorphology studies. For instance, movement of sand dunes in arid regions towards urban and rural areas, changes in aquifers as affecting the morphology, movements of glaciers (Owen et al., 2009; Frey and paul, 2012; Intrieri et al., 2013) and activities of volcanoes (Intrieri et al., 2013; Ebmeier et al., 2012; Nolesini et al., 2013; Wadge et al., 2011; Tralli et al., 2005) and earthquake deformations (Goudarzi et al., 2011; Tralli et al., 2005; Champenois et al., 2012) implies the importance of INSAR technology in geomorphology. Production of a consecutive images of SAR data in a wide span with a proper spatial resolution and acceptable accuracy provided researchers with a powerful tool to investigate different subjects in environmental hazards of earthquake (Ruch et al., 2008), subsidence (Gutierrez et al., 2011; Ebmeier et al., 2012; Lucha et al., 2012), landslides (Liu et al., 2013; Lauknes et al., 2010; Tralli et al., 2005), water level changes (Liu et al., 2013; Tralli et al., 2005), fluvial systems (Bertani et al., 2013; Gutierrez et al., 2011; Howard et al., 2012), erosion (Dalfsen et al., 2012), DEM and topographic maps development (Zhao et al., 2012; Kervyn, 2001), coastal changes (Garcia and Mahan, 2012; Tralli et al., 2005), sand dune movements in deserts. The capabilities of INSAR are not well understood in the studies of geomorphology and hydrology. It has been used for displacement and deformation in different fields of study, but what makes it important in geomorphology is a geomorphologic interpretation of the results of these analyses. After the interpretation of the results of INSAR in any field of study we can find the prevailing processes by detecting changes in landforms. Using rates of deformations in the morphologies of the earth it is possible to relate these values with the strength and behavior of the processes influencing these forms. The results, so far, were mainly discussed in theory as a technology of remote sensing. There are rarely interpretations of the results in terms of geomorphology to make it possible for a useful application in urban and rural development management, environmental hazards and tourism. Therefore, the results of INSAR can better be used by geomorphologic interpretations of earth surface features and events for a more accurate management and decision making.

\section{INSAR INTERPRETATION IN GEOMORPHOLOGY}

\subsection{Landslides}

In most cases the indication of mass movements by InSAR data is based on ground based SAR interferometry (Xiaobing,2009; Tarchi et al., 2003). There are lots of evidence about measurements of landslide movement by InSAR technique (Liu et al., 2013; Zhao et al., 2012; Handwerger et al., 2013; Rott and Nagler, 2006; Intrieri et al., 2013; Golestani and Wasowski, 2006; Tralli et al., 2005). These analyses can provide the researchers with available information to find the landslide areas and the prevailing processes for these landform changes. The results can represent the vulnerable areas for regional planning studies and environmental changes.

\subsection{Land subsidence}

Nowadays, technique of InSAR is one of the most important tools to examine the surface deformation by different processes. Land subsidence was frequently measured and analysed in different evidences (Dehghani et al., 2006; Gutierrez et al., 2011; Ebmeier et al., 2012; Lucha et al., 2012; Rigo et al., 2013; Zhao et al., 2012). Fan et al., (2011) indicated that the land subsidence can accurately be measured and analysed with Differential Interferometric Synthetic Aperture Radar (DInSAR) technique for a wide areas. Poland et al., (2006) with study of deformations by steady subsidence in California attributed the form changes somewhat to tectonic processes. Luchaet al., (2012) studied changes in fluvial landforms and subsidence and attributed these changes to desolusion of evaporites and Karstifications. Bawden et al., (2001) found the seasonal deformations in subsidence and uplifting due to the process of recharge in ground water table. Osmanoglu et al., (2008) studied the subsidence in mexicocityurban area as a hazard and found it due to the process of lowering in ground water level. The studies in arid areas had more accurate results than those in mountainous areas.

\subsection{Geomorphology map development}

With InSAR technology this is possible to generate high quality geomorphology maps from earth surface terrains. This help to distinguish geomorphology units easily particularly in forest areas with huge vegetation cover (Zhao et al., 2012; Kervyn, 2001). It also made it possible to obtain the knowledge of topographic features in inhospitable areas including hot deserts or mountain summits (Barzegar, 2005).

\subsection{Volcanology}


Magma activity beneath the earth surface would have morphological variations in earth surface. Using InSAR this can be detected and modeled to prevent probable devastating volcanic eruptions. As optical images are not very suitable for detection in very humid areas, Radar images with the technology make the required data easily achievable for researcher (Zhong, 2007). The technology is widely used for vertical movements and landform deformations by volcanos (Intrieri et al., 2013; Ebmeier et al., 2012; Nolesini et al., 2013; Wadge et al., 2011; Tralli et al., 2005; Amelung et al., 2000; Massonnet et al., 1995; Kampes,2006).

\subsection{Sand dune movements}

The movements and migration of sand dunes can be measured in desert areas for environmental, archeological, and mine studies. With two frequency radar system that employs two bands of VHF and Ka the InSAR technology may have the application to estimate the volume of the dunes. In that, by these two bands radar waves can penetrate into the sand and generate topographic maps of the terrains below the dunes. The advance of sand dune can be monitored to prevent the hazards of enveloping of settlements in near desert areas by huge dunes.

\subsection{Ice and glacier movements}

As radar technology use microwave spectral bands transmitted by satellite antennae instead of emitted waves from earth surface reflectance, this can be used to estimate the volume of ice in polar areas and in mountain glaciers every time it is required. Radar waves penetrate into the ice and snow and can produce topographic maps of the terrains below the glacier areas (Soheyli, 2010). By InSAR technology the migration of ice masses can be measured to show their rate of movement (Mobasheri, 2010) and its relationship as a process in forming glacier landforms. The movement of floating ice caps and icebergs and their volume and position can be explored to know their influence in coastal landforms by marine waves (Vajedian, 2008).

\section{CONCLUSION}

Geomorphology as an interdisciplinary field mainly has relations both with physical environment and human society. Landforms and their evolution in surface of the earth and height characteristics of physical terrain in an area and the influence of different processes is mainly emphasized in geomorphology. The effects of elevation variations and distribution in different area upon human activities is very important for study of environmental hazards and other environmental and planning researches in geomorphology. In one hand, geomorphology is mainly concerned with landforms and elevation and their evolution and, on the other hand, the InSAR technology is mainly applicable for elevation studies on earth surface. Therefore, the technology can be specifically employed for geomorphologic researches.

\section{Acknowledgement}

The financial support of University of Tehran and Vernal Institute is greatly appreciated.

\section{References}

Amelung, F.,;Jonssen,S; Zebker, H. Segall,P., 2000, Widespread uplift and trap door faulting on Galapagos volcanoes observed with radar interferometry. Nature 407, 993996

Andersson J. Ruch, T.R. Walter, M. Motagh, 2008,Calderascale inflation of the Lazufre volcanic area, South America: Evidence from InSAR , Journal of Volcanology and Geothermal Research 174, 337-344

Barzegar, F., 2005, Radar and Geology, Geography Learning Magazine 40, 26-30 (in Farsi)

Bawden.G; Thatcher.W;stein,R.S; hudnutKW; Peltzer,G.2001, Tectonic contraction across Loss Angeles after removal of groundwater pumping effects, 412, 812-8151

Carbognina, L; Teatini,P; and Tosi. L; 2004; Eustacy and Land subsidence in the Venice Lagoon at the beginning of the new millennium, J. Marine Syst 51, 345-353

Champenois J., B. Fruneau, E. Pathier, B. Deffontaines, K.C.Lin, J.-C. Hu, 2012, Monitoring of active tectonic deformations in the Longitudinal Valley (Eastern Taiwan) using Persistent ScattererInSAR method with ALOS PALSAR data, Earth and Planetary Science Letters 337-338, 144-155

Chatterjee R.S., Saha S.K, Suresh Kumar, Sharika Mathew, R.C. Lakhera, V.K. Dadhwal, 2009, Interferometric SAR for characterization of ravines as a function of their density, depth, and surface cover, ISPRS Journal of Photogrammetry and Remote Sensing 64, 472-481

Ebmeier S.K, J. Biggs, T.A. Mather, J.R. Elliott, G. Wadge, F. Amelung, 2012, Measuring large topographic change with InSAR: Lava thicknesses, extrusion rate and subsidence rate at Santiaguito volcano, Guatemala, Earth and Planetary Science Letters 335-336, 216-225

Ferretti, A; Prati, C; Rocca, F. Permanent scatterers in SAR interferometry, IEEE Trans, Geosci, Remot.Sen 39, 8-20

García Antonio F., Shannon A. Mahan, 2012, , The influence of upper-crust lithology on topographic development in the central Coast Ranges of California, Geomorphology 138, 243-262

Goudarzi Mohammad Ali, TsehaieWoldai, Valentyn A. Tolpekin, 2011, Surface deformation caused by April 6th 2009 earthquake in L'Aquila (Italy): A comparative analysis from ENVISAT ASAR, ALOS PALSAR and ASTER, International Journal of Applied Earth Observation and Geoinformation 13, 801-811

Gutiérrez, Francisco, Jorge Pedro Galve, Pedro Lucha, Carmen Castañeda, Jaime Bonachea, Jesús Guerrero, 2011, Integrating geomorphological mapping, trenching, InSAR and GPR for the identification and characterization of sinkholes: A review and application in the mantled evaporite karst of the Ebro Valley (NE Spain), Geomorphology 134, 144-156

IntrieriEmanuele, Federico Di Traglia, Chiara Del Ventisette, Giovanni Gigli, Francesco Mugnai, Guido Luzi, Nicola Casagli, 2013, Flank instability of Stromboli volcano (Aeolian Islands, Southern Italy): Integration of GB- InSAR and geomorphological observations, Geomorphology in press

Kervyn François, SamwelAyub, RugaibuhamuKajara, ElikundaKanza, Brian Temu, 2006, Evidence of recent faulting in the Rukwa rift (West Tanzania) based on radar interferometric DEMs, Journal of African Earth Sciences 44, 151-168 
Kruse Fred A., 2012, , Mapping surface mineralogy using imaging spectrometry, Geomorphology 137, 41-56

Lauknes T.R., A. PiyushShanker, J.F. Dehls, H.A. Zebker, I.H.C. Henderson, Y. Larsen, 2010, Detailed rockslide mapping in northern Norway with small baseline and persistent scattererinterferometric SAR time series methods, Remote Sensing of Environment 114, 2097-2109

Liu Peng, Zhenhong Li, Trevor Hoey, CemKincal, Jingfa Zhang, QimingZeng, Jan-Peter Muller, 2013, Using advanced InSAR time series techniques to monitor landslide movements in Badong of the Three Gorges region, China, International Journal of Applied Earth Observation and Geoinformation 21, 253-264

Lucha, Pedro, Gutiérrez Francisco, Jorge Pedro Galve, Jesús Guerrero, 2012, ,Geomorphic and stratigraphic evidence of incision-induced halokinetic uplift and dissolution subsidence in transverse drainages crossing the evaporite-cored BarbastroBalaguer Anticline (Ebro Basin, NE Spain), Geomorphology 171-172, 154-172

Massonnet, D., Briole,P, and Arnaud, A., 1995, Deflation of Mount Etna monitored by spaceborne radar interferometry, Nature 375, 567-570

Metternicht Graciela, Lorenz Hurni, RaduGogu, 2005, Remote sensing of landslides: An analysis of the potential contribution to geo-spatial systems for hazard assessment in mountainous environments, Remote Sensing of Environment 98, 284-303

Mobasheri, M. R., 2010, fundamentals of Physics in remote sensing satellite technologies, KhajehNasir University of Technology Press, 124 (in Farsi)

Murray, A. Brad, Eli Lazarus, Andrew Ashton, Andreas Baas, Giovanni Coco, Tom Coulthard, Mark Fonstad, Peter Haff, Dylan McNamara, Chris Paola, Jon Pelletier, Liam Reinhardt, 2009, Geomorphology, complexity, and the emerging science of the Earth's surface, geomorphology103, 496-505

Nolesini Teresa, Federico Di Traglia, Chiara Del Ventisette, SandroMoretti, Nicola Casagli, 2013, Deformations and slope instability on Stromboli volcano: Integration of GB InSAR data and analog modeling, Geomorphology 180-181, 242-254

Osmanoglu.B, Dixon.T, et al, 2011, Mexico City subsidence observed with persistent scattererInSAR, international Journal of Applied Earth Observation and Geoinformation 13, 1-2

Rigo Alexis, Marta Béjar-Pizarro, José Martínez-Díaz, 2013, Monitoring of Guadalentín valley (southern Spain) through a fast SAR Interferometry method, Journal of Applied Geophysics 91, 39-48

Rossetti D.F., T.C. Bertani, H. Zani, E.H. Cremon, E.H. Hayakawa , 2012,Late Quaternary sedimentary dynamics in Western Amazonia: Implications for the origin of open vegetation/forest contrasts, Geomorphology 177-178, 74-92

Rott, H.Scheuchl, B.; Siegel A; and Grasemann, B. 1999, Monitoring very slow slope motion by means of SAr interferometry: a case study from a mass waste above a reservoir in Otzal Alps, Austria. Geophys. Res. Lett., 26, 16291632

RiddickS.N., D.A. Schmidt, N.I. Deligne, 2012,,An analysis of terrain properties and the location of surface scatterers from persistent scatterer interferometry, ISPRS Journal of Photogrammetry and Remote Sensing 73, 50-57

Sack, D., Orme, A.R., 2013, Introduction to foundations of Geomorphology, Treaties of Geomorphology1, 1-10

Soheyli Far, M. R., 2010, RADAR, Aylar Press, Vol. 1, 50 (in Farsi)

Strozzi, T.; Farina, P.; Corsini, A.; Ambrosi, C.; Thuring, M.; Zilger, J.; Wiesmann, A.; Wegmuller, U.; and Werner, C. 2005, Survey and monitoring of landslide displacements by means of L-band satellite SAR interferometry. Landslides 2, 193-201

T.R. Lauknes, A. PiyushShanker, J.F. Dehls, H.A. Zebker, I.H.C. Henderson, Y. Larsen, 2010, Detailed rockslide mapping in northern Norway with small baseline and persistent scattererinterferometric SAR time series methods, Remote Sensing of Environment 114, 2097-2109

Takada Youichiro, Masato Furuya, 2010,Aseismic slip during the 1996 earthquake swarm in and around the Onikobe geothermal area, NE Japan Earth and Planetary Science Letters 290, 302-310

Tralli David M., Ronald G. Blom, Victor Zlotnicki, Andrea Donnellan, Diane L. Evans, 2005, Satellite remote sensing of earthquake, volcano, flood, landslide and coastal inundation hazards, ISPRS Journal of Photogrammetry and Remote Sensing 59, 185-198

Wadge G., P. Cole, A. Stinton, J.-C.,Komorowski, R. Stewart, A.C. Toombs, Y. Legendre, 2011, Rapid topographic change measured by high-resolution satellite radar at Soufriere Hills Volcano, Montserrat, 2008-2010, Journal of Volcanology and Geothermal Research 199, 142-152

Waele Jo De, Gutiérrez Francisco, Mario Parise, Lukas Plan, 2011, Geomorphology and natural hazards in karst areas: A review, Geomorphology 134, 1-8

Wechsler Neta, Thomas K. Rockwell, Yehuda Ben-Zion , 2009,Application of high resolution DEM data to detect rock damage from geomorphic signals along the central San Jacinto Fault, Geomorphology 113, 82-96

Zhao Chaoying, Zhong Lu, Qin Zhang, Juan de la Fuente, 2012, Large-area landslide detection and monitoring with ALOS/PALSAR imagery data over Northern California and Southern Oregon, USA ,Remote Sensing of Environment 124, 348-359

Zhou Huifang, Jingfa Zhang, Lixia Gong, Xiaoqing Shang, 2012,Comparison and Validation of Different DEM Data Derived from InSAR, Procedia Environmental Sciences 12, 590-597

Zhou Xiaobing, Ni-Bin Chang,Shusun Li, 2009 , Applications of SAR Interferometry in Earth and Environmental Science Research, Sensors 9, 1876-1912 